Article

\title{
One-Pot, In-Situ Synthesis of 8-Armed Poly(Ethylene Glycol)-Coated Ag Nanoclusters as a Fluorescent Sensor for Selective Detection of $\mathrm{Cu}^{2+}$
}

\author{
Xiaoyuan Zhang ${ }^{1}$, Guanghua Zhang ${ }^{1}$, Gang Wei ${ }^{2, *}$ and Zhiqiang Su $1, *(\mathbb{B}$ \\ 1 Beijing Key Laboratory of Advanced Functional Polymer Composites, State Key Laboratory of Chemical \\ Resource Engineering, Beijing University of Chemical Technology, Beijing 100029, China; \\ 2020700036@mail.buct.edu.cn (X.Z.); 2018210201@mail.buct.edu.cn (G.Z.) \\ 2 College of Chemistry and Chemical Engineering, Qingdao University, Qingdao 266071, China \\ * $\quad$ Correspondence: weigroup@qdu.edu.cn (G.W.); suzq@mail.buct.edu.cn (Z.S.); Tel.: +86-150-6624-2101 (G.W.)
}

Received: 11 August 2020; Accepted: 21 September 2020; Published: 23 September 2020

check for updates

\begin{abstract}
Fluorescent nanomaterials, such as quantum dots, have developed rapidly in recent years and have been significantly developed. Herein, we demonstrate a facile, one-pot, and in-situ synthesis strategy to obtain fluorescent silver nanoclusters (AgNCs) coated with eight-armed poly (ethylene glycol) polymers (8PEG-AgNCs) via a direct gel-mediated process. During the synthesis, ammonium $\left(\mathrm{NH}_{3}\right)$ served as the crosslinker for the gel formation via a amine-type Michael addition reaction. This hydrogel can be used as a template to synthesize AgNCs using its volume-limiting effect. The in-situ generation of AgNCs takes place inside the nanocages of the formed gels, which guarantees the homogenous distribution of AgNCs in the gel matrix, as well as the efficient coating of PEG on the nanoclusters. After the degradation of gels, the released 8PEG-AgNCs nanohybrids showed strong blue fluorescence and exhibited long-term stability in aqueous solution for nearly one year. Results showed that the fabricated sensor revealed excellent fluorescent sensitivity for the selective detection of $\mathrm{Cu}^{2+}$ with a detection limit of $50 \mathrm{nM}$ and a wide linear detection range of 5-100 $\mu \mathrm{M}$. It is proposed that the greater cross-linking density leads to smaller gel pores and allows the synthesis of AgNCs with fluorescent properties. These results indicate that this novel hydrogel with certain biodegradation has the potential to be applied as a fluorescent sensor for catalytic synthesis, fluorescence tracing in cells, and fluorescence detection fields. Meanwhile, the novel design principle has a certain versatility to accelerate the development and application of other kinds of metal nanoclusters and quantum dots.
\end{abstract}

Keywords: hydrogel; silver nanoclusters; fluorescent sensor; $\mathrm{Cu}^{2+}$ ion; bionanomaterials; environmental science

\section{Introduction}

In the past few decades, fluorescent metal nanoclusters (usually less than $2 \mathrm{~nm}$ in diameter), consisting of several to a few hundred atoms, have been widely utilized in the fields of biosensing, bioimaging, as well as diagnostics [1-6], due to their facile synthesis, strong photoluminescence and high photostability $[7,8]$. In particular, silver nanoclusters (AgNCs) exhibit stronger fluorescence than other metal nanoclusters, and possess some unique applications, such as in antimicrobials [9-11]. However, AgNCs in aqueous solution are highly susceptible to oxidization, and easily undergo aggregation to form plasmonic particles at ambient temperatures [12-14]. Therefore, various additives, such as thiolates [15], dendrimers [16], polymers [17], and some biomolecules, including peptides [18], proteins [19], and DNA [20], have been employed to synthesize and stabilize AgNCs. The use of polyethylene glycol (PEG) long chains [21] or branched chains such as star polymers [22] as templates 
to prepare nanomaterials as a common method has often been reported in the previous literature. For PEG hydrogels used as templates, the stability and biodegradability of the hydrogels for gel formation are particularly important. In the same way, commonly used template materials, such as glass [23], DNA [24,25], polymethacrylic acid [26], peptides [18], and micelles [27], were utilized for preparing quantum dots. In these cases, the hydrogel materials can achieve size control of quantum dots through a certain volume-limiting effect [27].

Although many effective works have been carried out, there are still some challenges in this research field. For instance, additional reducing agents were required in some cases, such as Hydrazine hydrate [28]. This kind of reducing agents are very dangerous to human health [29]. Furthermore, the long-term stability was not acceptable and the control during nanocluster growth was absent. Moreover, the biocompatibility against fibroblast cells and the biodegradation ability of the materials were poor [30-32].

Recently, hydrogels, which are insoluble in water yet capable of absorbing water and exhibit three-dimensional (3D) network structures and are composes of molecular nanocages, have been used to control the nucleation and growth of the nanoclusters [22,33-37]. The hydrogel material as a template to prepare nanomaterials such as quantum dots should also have the following properties: (i) The template is able to maintain its properties stable during the reaction process. (ii) It is able to provide the physical and chemical effects necessary for crystal growth such as a limiting effect to limit the crystal volume growth, a certain coordination complexation effect to stabilize the nucleus, a suitable reaction environment, a uniform and slow reduction to prevent agglomeration. (iii) The prepared quantum dot material can be easily separated out. So far, the only hydrogel templates that can fully meet the above conditions are the peptide hydrogel templates formed by self-assembly [38] and the phenolic templates with higher strength [39], etc. However, these materials require strictly controlled reaction conditions, and cannot be used as a general and extensive template to prepare quantum dot materials.

Cage dimensions and kinetic parameters of 3D hydrogels are key factors to mediate the nanocluster growth and yield the desired size of nanoclusters. For example, Chakraborty et al. reported reducing $\mathrm{Ag}(\mathrm{I})$ thiolates to form AgNCs in polyacrylamide gels' nanocages [36]. In their method, the monomers containing $\mathrm{Ag}(\mathrm{I})$ thiolates polymerized to form a gel; afterwards, the reducing agent, aqueous $\mathrm{NaBH}_{4}$, was added, and then the color changed from light yellow to dark brown, indicating the formation of AgNCs inside of the nanocages. Although the monodisperse AgNCs were obtained, most of the formed clusters were trapped inside the gel and the released clusters lacked polymer modification due to the weak degradation ability of the gel matrix.

So far, there is no work regarding hydrogel materials prepared from PEG as nanoscale reactors and templates for AgNCs. Thus, we proposed and developed a novel, one-pot and low-cost method for in-situ synthesizing of AgNCs with long-term stability, uniform size, and strong photoluminescence via a gel-mediated process (Figure 1). As the gelation is proceeding, the growth of AgNCs takes place at the same time without additional reducing agent. Unlike other gel template, our gels could be totally degraded in a few days and release eight-armed poly(ethylene glycol) (8PEG)-coated AgNCs, which are still finely dispersed in aqueous solution and exhibit bright fluorescence after one year storage at room temperature in a glass bottle. Moreover, these luminescent 8PEG-AgNCs nanohybrids are selectively sensitive to $\mathrm{Cu}^{2+}$ through fluorescence quenching, which can serve as an effective fluorescent sensor for $\mathrm{Cu}^{2+}$ ion detection. The novel gel-mediated method to a prepare polymer-NCs hybrid system with a versatile architecture, long-term stability and unique NC releasing ability via degradation opens a new avenue for designing advanced polymer-NCs functional materials. 

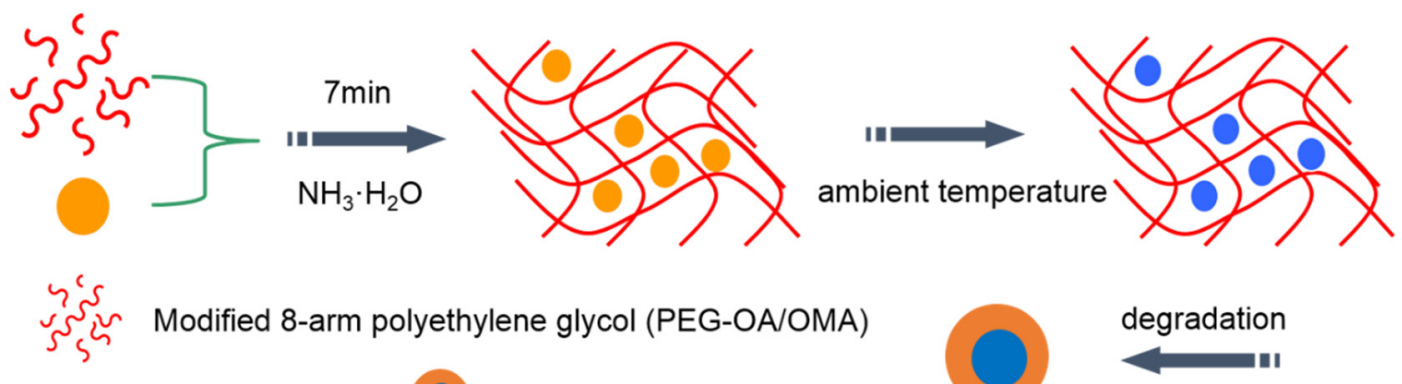

$\mathrm{Ag}^{+} \bigcirc$ AgNCs $\bigcirc$ AgNCs coating with PEG
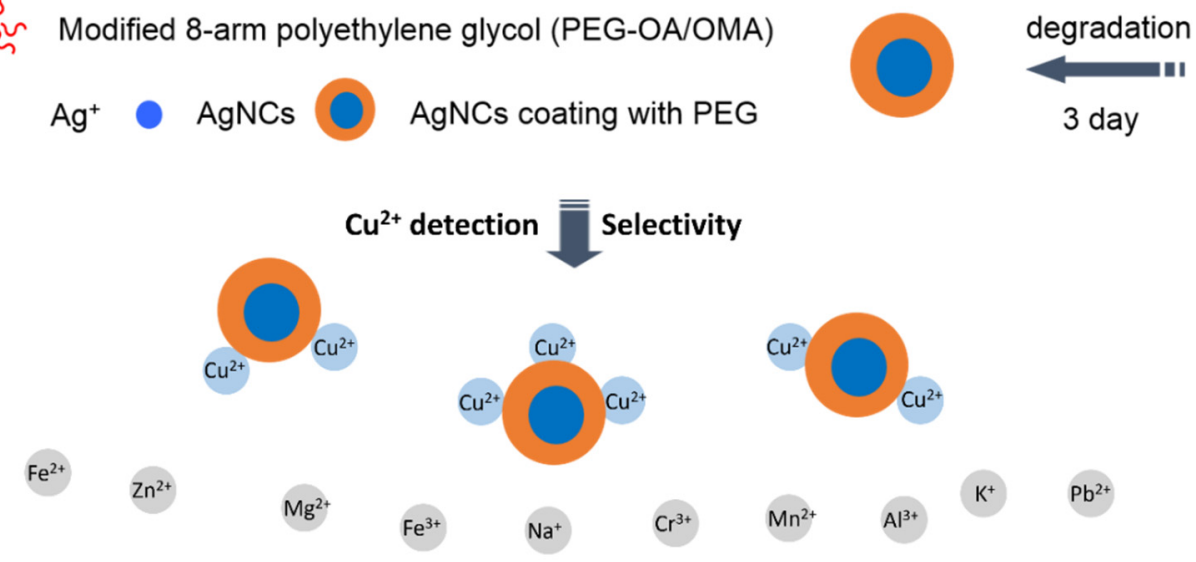

Figure 1. Schematic description for synthesizing fluorescent silver nanoclusters (AgNCs) coated with 8-armed poly (ethylene glycol) (8PEG) polymers and selective detection for $\mathrm{Cu}^{2+}$ ions.

\section{Materials and Methods}

\subsection{Materials}

Eight-armed poly(ethylene glycol) (8PEG-OH, Mw $15 \mathrm{KDa}$ ) was purchased from Jenkem technology USA. Eight-arm poly(ethylene glycol) acrylate (8PEG) was prepared via the same procedure as we have reported before [1]. Polyethylene glycol diacrylate (PEGDA, $\mathrm{Mw}=2 \mathrm{kDa}$ ), 2-isocyanatoethylmethacrylate (purity 98\%) and acryloyl chloride (purity 97\%) were from TCI (Tokyo, Japan), tetrahydrofuran (THF, super dry solvent), ammonia water $(37 \% w / w)$, alkaline aluminum oxide, dibutyltin dilaurate were purchased from J\&K (Beijing, China). All the metal ions were in the nitrate form and were purchased from Beijing Chemical Co. (Beijing, China). Other reagents were purchased from Aldrich and used as received unless stated otherwise. Solvents were at least analytical grade quality.

\subsection{Synthesis of Acryloyl Chloride Modified 8-Armed Polyethylene Glycol (PEGOA)}

First, 8 PEG-OH (5 g) with a hydroxyl capped end was synthesized at $60^{\circ} \mathrm{C}$ in a dried vacuum oven for $4 \mathrm{~h}$. 8PEG-OH was dissolved in $50 \mathrm{~mL}$ of dichloromethane in a super dry solvent under nitrogen atmosphere, and then placed into the solution in an ice water bath. Then $4 \mathrm{~g}$ of sodium carbonate was added to the mixture to neutralize the esterification reaction to produce the acid. The solution was stirred and reacted with a magnetic stirrer at $35^{\circ} \mathrm{C}$ under a continuous nitrogen flow for 4 days. The reacted solution was filtered through an alkaline alumina column to remove the insoluble solids and the acid generated during the reaction. The solution was evaporated by vacuum at $20^{\circ} \mathrm{C}$, until a certain concentration and then dropped into an excess of cooled anhydrous ethyl ether $\left(<4{ }^{\circ} \mathrm{C}\right)$. The sediment was collected in a centrifuge tube with constant and rapid stirring and centrifuged (5000 rpm for $15 \mathrm{~min}$ ). The lower layer was precipitated, and the precipitate was dried in a vacuum drying oven at $40{ }^{\circ} \mathrm{C}$ for $6 \mathrm{~h}$ to obtain a white powdery solid, and the yield was calculated after weighing. The reduction rate was measured to be $72 \%$. 


\subsection{Synthesis of 8-Armed Polyethylene Glycol (PEGOMA) Capped with Methacrylate (2-Isocyanoethyl) Ester}

The 8PEG-OH (2 g) was dissolved in $50 \mathrm{~mL}$ of THF. An amount of $0.6 \mathrm{~mL}$ of methacrylic acid (2-isocyanoethyl) ester was added to THF super-dry solvent by pipetting with vigorous agitation. An amount of $30 \mu \mathrm{L}$ of dibutyltin dilaurate was used as the catalyst. The solution was bubbled under nitrogen for $10 \mathrm{~min}$ and then reacted in a water bath at $60{ }^{\circ} \mathrm{C}$ for $20 \mathrm{~h}$. The solution was evaporated in a vacuum at $30^{\circ} \mathrm{C}$ until about $10 \mathrm{~mL}$ of solvent remained. The solution was evaporated in a vacuum at $30^{\circ} \mathrm{C}$ until about $10 \mathrm{Ml}$ of solvent remained, and then the solution was added drop by drop to a $150 \mu \mathrm{M}$ solution. The ether was used to obtain a suspension containing a white floc-like precipitate. The precipitate and the suspension were centrifuged at high speed for $15 \mathrm{~min}$ (5000 rpm). The supernatant was discarded, and the bottom was vacuum-dried at $30{ }^{\circ} \mathrm{C}$. After $2 \mathrm{~h}$ of drying in a drying chamber, the desired product was obtained as a white bulk solid with a yield of $94 \%$ after weighing.

\subsection{Determination of the Critical Gelation Concentration of PEGOMA and PEGOA Hydrogels}

The critical gelation concentrations of PEGOMA and PEGOA hydrogels were determined by the inversion method. The purified PEGOMA and PEGOA were weighed accurately, and 0.1-3 mL of each was added. A volume of primary water, sonicated for half an hour in an ultrasonic cleaner, was used to dissolve the sample from different concentrations and dissolved in a $5 \mathrm{~mL}$ centrifuge tube. An amount of $50 \mu \mathrm{L}$ of ammonia was added separately with a pipette gun and then quickly the solution was ultrasonicated for $1 \mathrm{~h}$. The critical gelling concentration is the minimum concentration at which the solution stops flowing after tilting or inverting the test tube.

\subsection{Determination of Gelation Time of PEGOMA and PEGOA Hydrogels}

The gelation time of the hydrogels was determined by the inversion method, and $150 \mathrm{mg}$ of PEGOMA and PEGOA were weighed multiple times. The hydrogels were dissolved in $150 \mathrm{~mL}$ of primary water and sonicated for half an hour to obtain a clear solution. An amount of $30 \mu \mathrm{L}$ of ammonia was added at different concentrations to the solution by pipetting, then the tube was shaken rapidly and placed in the ultrasonic washer for $10 \mathrm{~s}$. Simultaneously, a stopwatch was started. The tube was tilted or inverted every few seconds to obtain the PEGOMA and PEGOA solutions.

\subsection{In-Situ Synthesis of AgNCs Using 8PEG-NH $\mathrm{H}_{3}$ Hydrogel as Template}

After mixing $150 \mathrm{mg}$ of $8 \mathrm{PEG}$ polymer with certain amounts of distilled water in a $5 \mathrm{~mL}$ plastic centrifuge tube, $20 \mu \mathrm{L}$ of $\mathrm{AgNO}_{3}$ solution $(100 \mathrm{mg} / \mathrm{mL}$ in water) was injected and then ultrasonicated for $20 \mathrm{~min}$ to form a homogenized solution. Then, $50 \mu \mathrm{L}$ of ammonia solution was injected. The tube was violently shaken and then ultrasonicated for $2 \mathrm{~min}$ to remove bubbles. The solution turned into hydrogel in 5-30 min according to the concentration of 8PEG solution. Colorless and fluorescent 8PEG-AgNCs solution could be obtained after the degradation process.

\subsection{Detection of the $\mathrm{Cu}^{2+}$ Ions Using the 8PEG-AgNCs Nanohybrids}

A typical $\mathrm{Cu}^{2+}$ detection procedure was performed as follows. Copper nitrate was utilized for the study of $\mathrm{Cu}^{2+}$ detection. A $2 \mathrm{mM}$ stock solution of copper nitrate was prepared, from which various $\mathrm{Cu}^{2+}$ concentrations were obtained by serial dilution. For the fluorescence quenching studies, aqueous solutions of 8PEG-AgNCs and $\mathrm{Cu}^{2+}$ with different concentrations were mixed, and further equilibrated for $10 \mathrm{~min}$ before the fluorescence spectral measurements. The preliminary investigation indicated that the reaction could reach equilibrium within $10 \mathrm{~min}$. In order to evaluate the selectivity of $\mathrm{Cu}^{2+}$ fluorescence detection by using 8PEG-AgNCs nanohybrids, other metal ions such as $\mathrm{Hg}^{2+}$, $\mathrm{Fe}^{2+}, \mathrm{Zn}^{2+}, \mathrm{Mg}^{2+}, \mathrm{Fe}^{3+}, \mathrm{Na}^{+}, \mathrm{Cr}^{3+}, \mathrm{Mn}^{2+}, \mathrm{Al}^{3+}, \mathrm{K}^{+}$and $\mathrm{Pb}^{2+}$ were chosen to be tested and analyzed. All the measurements were conducted at least in triplicate. 


\subsection{Instruments and Measurements}

The UV/vis spectra and fluorescence spectra were obtained with a TU-1901 UV-visible spectrometer (Purkinje, Beijing, China) and F-7000 fluorescence spectrophotometer (AXimA-CFR, Hitachi, Japan), respectively. A drop of 8 PEG-AgNCs solution was put on a grid and dried for 30 min under an infrared lamp and then the samples were measured on a JEOL JEM-100 CX II TEM (JEOL, Tokyo, Japan) under an accelerating voltage of $100 \mathrm{kV}$. The high-resolution TEM (HRTEM) test was performed on a HRTEM JEM-3030F under 200 kV. Fluorescence quantum yield of the 8PEG-AgNCs nanohybrid was measured by a Quantaurus-QY absolute photoluminescence quantum yield spectrometer (Hamamatsu, Japan). A dynamic laser scattering (DLS) instrument (BI-90Plus) was used to analyze the size distribution of the 8PEG-AgNCs nanospheres. X-ray photoelectron spectroscopy (XPS) was conducted on an ESCALAB 250 X-ray photoelectron spectrometer (Thermofisher, Waltham, MA, USA) with a monochromatized Al K $\alpha$ X-ray source (1486.71 eV). Gel Permeation Chromatography (GPC) was performed at $25^{\circ} \mathrm{C}$ utilizing a Korean YL9100/YL9130 System with a refractive index detector.

\section{Results and Discussion}

\subsection{Analysis of the Gelling Process of PEGOMA and PEGOA Hydrogel Templates}

This section begins with the properties of the modified 8PEG hydrogels cross-linked with ammonia. The basic gelation properties and gelation principles of PEG hydrogels were initiated to determine the function of eight-armed PEG hydrogels in the process of template synthesis of AgNCs nanomaterials. The study of the gelation properties of hydrogels began with the critical gelation concentration of a hydrogel, which was the critical gelation concentration of a monomer as a sufficient cross-linker. That is to say, it is the lowest solution concentration that can form a gel without fragmentation under the circumstances. Firstly, $150 \mathrm{mg}$ of purified PEGOA and PEGOMA were dissolved in 0.1, 0.2, and $0.1 \mathrm{~mL}$, respectively. An amount of $50 \mu \mathrm{L}$ of primary water at various concentrations of $0.4,0.8,1.6$, and $3 \mathrm{~mL}$, etc. was added to ammonia. The critical gel concentration of PEGOA was measured at about $100 \mathrm{mg} / \mathrm{mL}$ half an hour after the sonication. In this system, the critical gel concentration of PEGOMA was about $180 \mathrm{mg} / \mathrm{mL}$. After the homogeneous solution, the gels were smooth, transparent and had some brittleness. Take PEGOA dissolved in $0.2 \mathrm{~mL}$ water as an example, the gel formed was as follows (Figure 2).

The gelation time of a hydrogel is one of the most important indicators for a hydrogel and can also be used to illustrate the cross-linking process of a hydrogel. PEGOMA hydrogels and PEGOA hydrogels are the most important crosslinking agents. The variation of gelation time of the hydrogel with the addition of cross-linker ammonia is shown in Figure 2. The gelation time of PEGOMA hydrogel is much shorter than that of PEGOA at the same ammonia concentration. The concentration of fixed end-modified un-crosslinked PEG remained unchanged, gradually decreasing from 40 to $2 \mu \mathrm{L}$ as ammonia was added. The gel time of PEGOMA hydrogel was gradually extended from 38 to $98 \mathrm{~s}$, and the gel time of PEGOA hydrogel from 5 min gradually extended to $168.3 \mathrm{~min}$. 


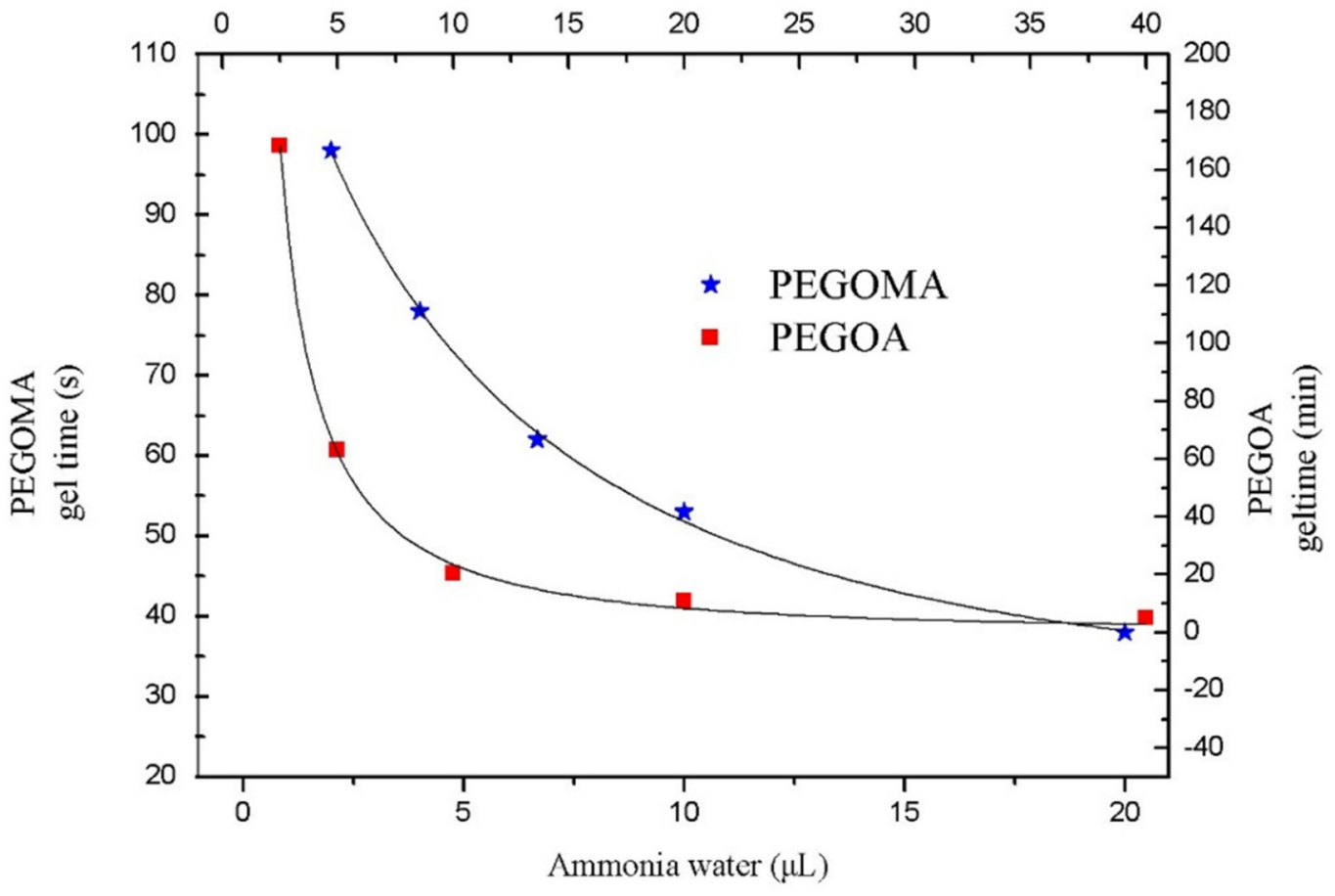

Figure 2. Gelation time changes of PEGOMA and PEGOA hydrogels with the added amount of ammonia water.

Therefore, the gel time of PEGOMA was much shorter than that of PEGOA. In methacrylate PEG, the methyl group can stabilize the negative charge formed by the Michael addition reaction. This reaction can generate tertiary carbon negative ions before recapturing hydrogen atoms. While the carbon anion can also be stabilized by conjugation, the activation energy of the reaction is low and irreversible. The double bond at the acrylate end is not stabilized by this effect, and the secondary carbon anion generated by the reaction cannot be stabilized, therefore, it cannot be stabilized. The process exists in the formation of PEGOA and can only generate an alkanol-like structure similar to the 1,4 addition. The reaction is slower and has a higher activation energy, and the possible mechanism of the reaction is shown in Figure 3.<smiles>C=C(C)C(=O)OCCNC(=O)OCCOC(=O)C(C)N</smiles>

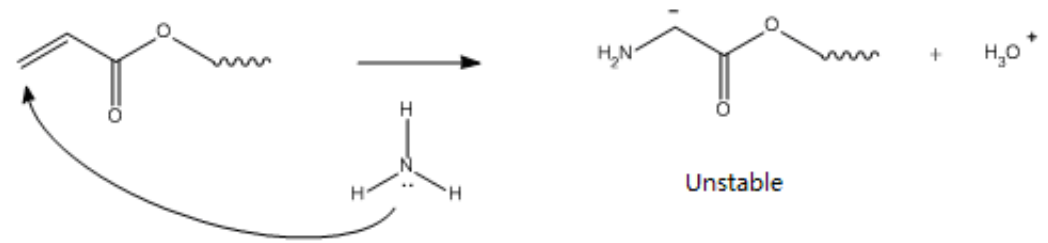

Figure 3. Mechanism of the Michael addition reaction of PEGOMA and PEGOA with ammonia water.

As can be seen from Figure 4, although both are PEG hydrogels, the pure PEGOA hydrogel has a higher water absorption and swelling rate. This indicates that the cross-linking density is greater and 
the cross-linking yields a more imperfect hydrogel network chain. With the addition of PEGOMA, the mass ratio of hydrogels shows a decreasing trend, indicating that ammonia speeds up the reaction and perfects the formation of the net chain. Another phenomenon observed from Figure 4 is that, when the PEGOMA content is less than $25 \%$, the degradation forms an aqueous solution of nanosilver clusters with fluorescent properties. In addition, when the PEGOMA content is $25-50 \%$, it forms a long-stable hydrogel with fluorescent properties under UV light, and a colorless transparent gel at room temperature. When the PEGOMA content was greater than 50\%, there was no fluorescence after the mixture was crosslinked and placed in water for a certain period of time, and only colorless transparent gels were present. In combination with the analysis of the pore size of the gel templates, this may be due to the synergistic effect from the silver ion reduction by the terminal hydroxyl group of the PEG degradation products and the limiting effect of the pore volume within the gel template.

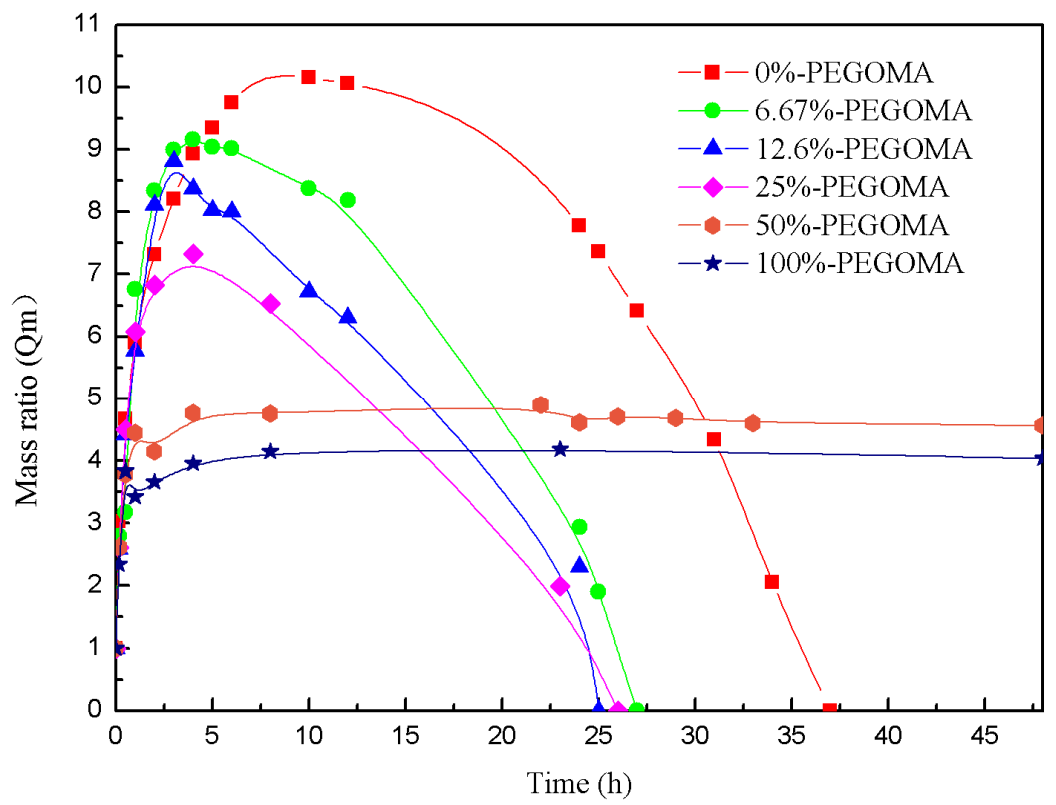

Figure 4. Mass ratio changes of different kinds of polyethylene glycol (PEG) hydrogel template (gels with different PEGOA/PEGOMA blending ratios) with time.

By characterizing the basic hydrogel properties, this section determines that the gel-forming concentration of the hydrogel template used to be $750 \mathrm{mg} / \mathrm{mL}$. It is reasonable for the cross-linking reaction to proceed smoothly, while not having to wait for a long time. The addition of $30 \mathrm{~mL}$ of ammonia was sufficient for the complete crosslinking reaction and a short crosslinking time.

\subsection{Fabrication of $8 P E G-A g N C s$ Nanohybrids}

Very recently, a new class of eight-armed star-shaped PEG-based hydrogels (8PEG-NH$\left.)_{3}\right)$ has been developed in our lab [40], in which ammonium solution $\left(\mathrm{NH}_{3}\right)$ serves as the crosslinker. They were formed by an amine Michael-type addition reaction between unsaturated carbon-carbon double bonds (acrylate end groups) and reactive amine species. By variation of the crosslinking parameters, the degree of residual functional groups, the swelling degree and the mechanical properties of the resulting gels can be elegantly tuned $[41,42]$.

Since the $\mathrm{NH}_{3}$ solution functions between two and three in practice, the fully modified eight-armed PEG has a functionality of eight. Compared to the synthesis of PEG hydrogels using a linear PEG (functionality of two) and a cross-linker (functionality of typically two), ammonia-crosslinked eight-armed PEG hydrogels can achieve a denser crosslink density and result in a denser inner pore size of the hydrogel. Theoretically, they could be applied as hyperbranched polymers and as templates 
for synthetic nanoclusters. Therefore, the strong fluorescent 8PEG-AgNCs hydrogels were formed when mixing $\mathrm{NH}_{3}$ solution with an $8 \mathrm{PEG}$ precursor containing $\mathrm{Ag}^{+}$ions.

The mechanism of using 8PEG-NH 3 hydrogel as template to obtain AgNCs could be explained by the synergistic effect of hydroxyl groups from 8 PEG as a reduction agent and the nanocages surrounded by crosslinking polymer chains as a nano reactor (cage effect). $\mathrm{Ag}^{+}$ions can be reduced to $\mathrm{Ag}^{0}$ clusters by the oxidation of hydroxyl groups from PEG in the absence of any other reducing reagents [43]. The reducing reactivity of PEG can be remarkably increased as the length of the PEG chain increases [44]. Moreover, amidogen can be introduced to the PEG chains through a Michael addition reaction [45], which could chelate with $\mathrm{Ag}^{+}$ions to stabilize AgNCs. Meanwhile, the oxygens on the PEG chains provide coordinate bonds with AgNCs and hence enhance their stability in aqueous solution. The stability was similar to the DNA-templated fluorescent AgNCs, developed by Sharma et al. [25].

Nanocages inside the 8PEG gel matrix is another key factor to obtain fluorescent AgNCs. The crosslinking structure of the 8PEG gel matrix has been supposed to result in a "cage effect" (Figure 1), which improves the stability of AgNCs and prevents continued growth of nanoclusters to larger nanoparticles [46]. Mixing the linear PEG (LPEG) solution containing $\mathrm{Ag}^{+}$ion with $\mathrm{NH}_{3}$ solution leads to larger plasmonic Ag nanoparticles (LPEG-AgNPs) rather than nanoclusters, this is because linear PEG reacted with $\mathrm{NH}_{3}$ cannot form a gel, indicating that "cage effect" plays a crucial role in the formation of AgNCs. Finally, due to the hydrolysis of ester groups in the gel matrix, 8PEG-AgNCs nanohybrids can be released via the gel's degradation.

GPC has been utilized to determine the molecular weight of degradation products, which are nearly identical to that of 8 PEG polymers. As can be seen from Figure 5, the molecular weight (Mn) of the degradation products of the PEG blended hydrogel was similar to that of the initial polymer. This probably due to the existence of some adsorption interaction between the end-modified groups and the gel column, which increased the retention time. No large change in retention time was observed during the synthesis and degradation process, which indicates that the preparation and degradation of the gel template did not show any molecular weight change or main chain breakage. The larger polydispersity coefficient (PD) of PEGOMA was 1.4774, while the other three were similar, probably due to a small number of ester exchange reactions in PEGOMA. These results suggest the possibility of the total degradation of the gel matrix, as well as the complete releasing of $8 \mathrm{PEG}-\mathrm{AgNCs}$, as illustrated in Figure 1.

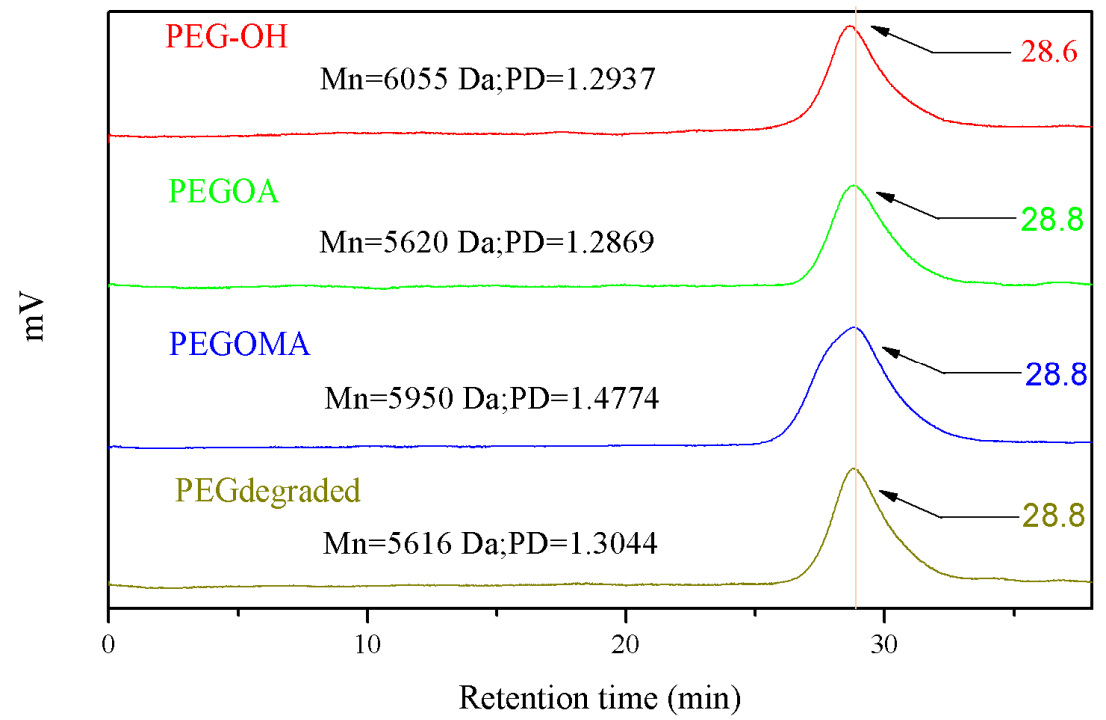

Figure 5. Gel Permeation Chromatography (GPC) analysis of 8PEG-OH, PEGOA, PEGOMA and degradation product of PEGOA-PEGOMA hybrid gel template. 
HRTEM images of the 8PEG-AgNCs are given in Figure 6a-c. The as-synthesized AgNCs are nearly spherical and well dispersed. The lattice fringes of AgNCs are clearly determined as $2.5 \AA$ corresponding to $\mathrm{d}(111)(0.18 \mathrm{~nm})$, proving the existence of $\mathrm{Ag}$ nano crystals [47]. The average diameter of AgNCs is $3.27 \mathrm{~nm}$ (Figure 6c), which is appreciably larger than most of the reported AgNCs. We suggest that is the result of AgNCs being densely covered by PEG chains, accounting for the excellent water solubility and sustainable fluorescence at room temperature.
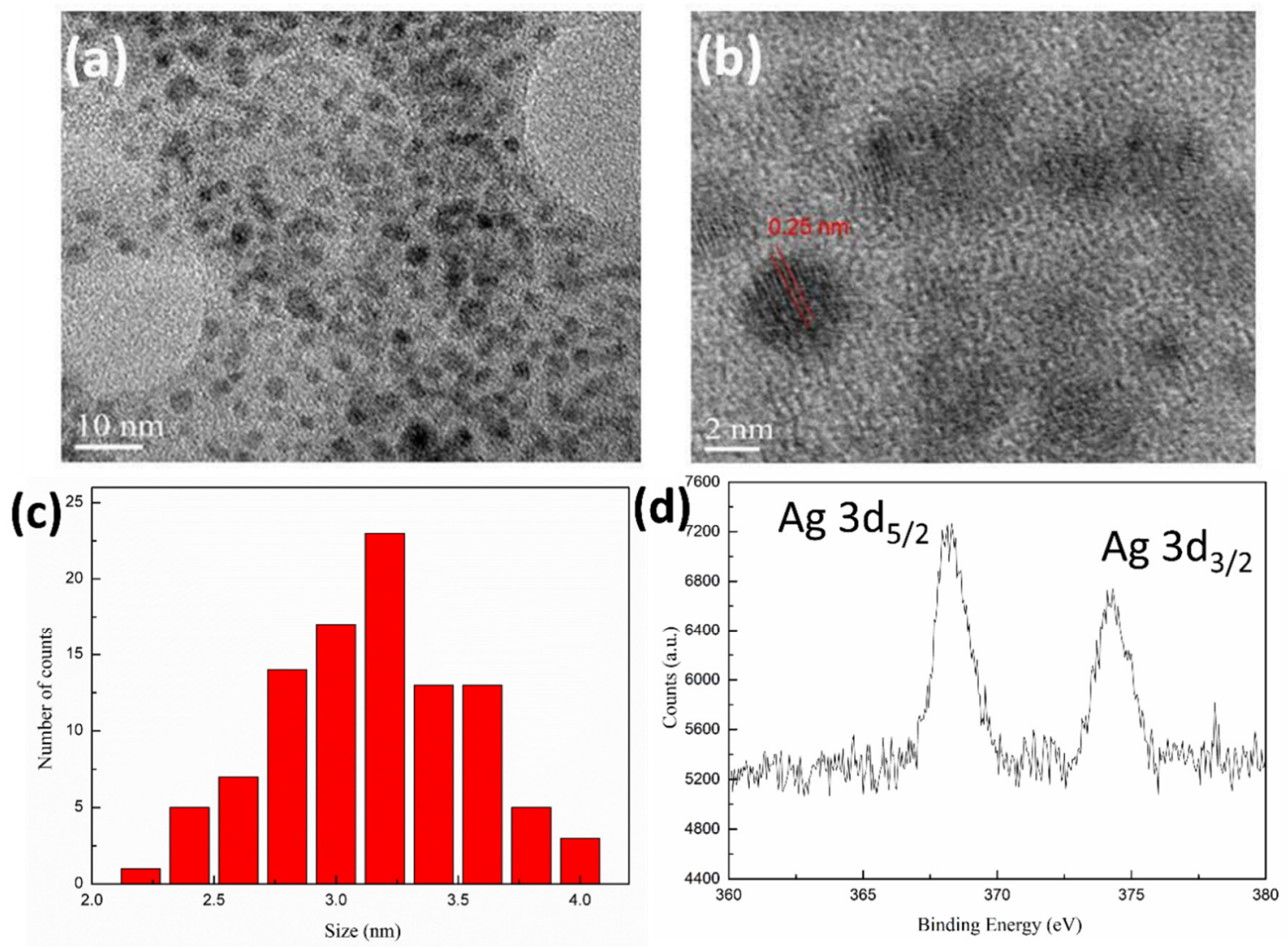

Figure 6. (a) High resolution (HR)TEM images of as-synthesized 8PEG-AgNCs nanohybrids, (b) Lattice fringes of AgNCs, (c) Particle size distribution and (d) X-ray photoelectron spectroscopy (XPS) characterization of $8 \mathrm{PEG}-\mathrm{AgNC}$.

The XPS wide spectrum of the 8PEG-AgNCs (Figure $6 \mathrm{~d}$ ) shows peaks at 282.2 and $529.5 \mathrm{eV}$, which are attributed to $\mathrm{C} 1 \mathrm{~s}$ and $\mathrm{O} 1 \mathrm{~s}$ from PEG chains, respectively. In addition, two peaks at 368.2 and $374.2 \mathrm{eV}$ are attributed to the binding energy of $\mathrm{Ag} 3 \mathrm{~d}$, in which a $6 \mathrm{eV}$ gap is in agreement with the zero valence of AgNCs [48]. DLS measurements of 8PEG-AgNCs in deionized water confirm a relatively narrow size distribution around $10 \mathrm{~nm}$ larger than the TEM diameter, revealing the core-shell structure of 8PEG-AgNCs.

\subsection{Fluorescent Properties of 8 PEG-AgNCs Nanohybrids}

Compared with other templates for the synthesis of AgNCs, the 8PEG material as a template for the preparation of AgNCs has different fluorescence properties in addition to the stable long-term stability of the synthesized AgNCs. The UV/vis absorption spectra and fluorescence spectra of fresh 8PEG-AgNCs, reserved 8PEG-AgNCs solution (stored in the dark, at room temperature for one year) and PEG-AgNPs are shown in Figure 7a,b, respectively. Both fresh and reserved 8PEG-AgNCs present a narrow absorption peak at $310 \mathrm{~nm}$ (Figure 7a), without the characteristic plasmon peak of larger AgNCs in the range of 400-500 nm, indicating the formation of AgNCs. On the contrary, the plasmonic 
peak of AgNCs appear in the spectra of the linear PEG solution. Due to no gel formation in the linear case of PEG, nanoclusters can continually grow to generate large-sized nanoparticles.
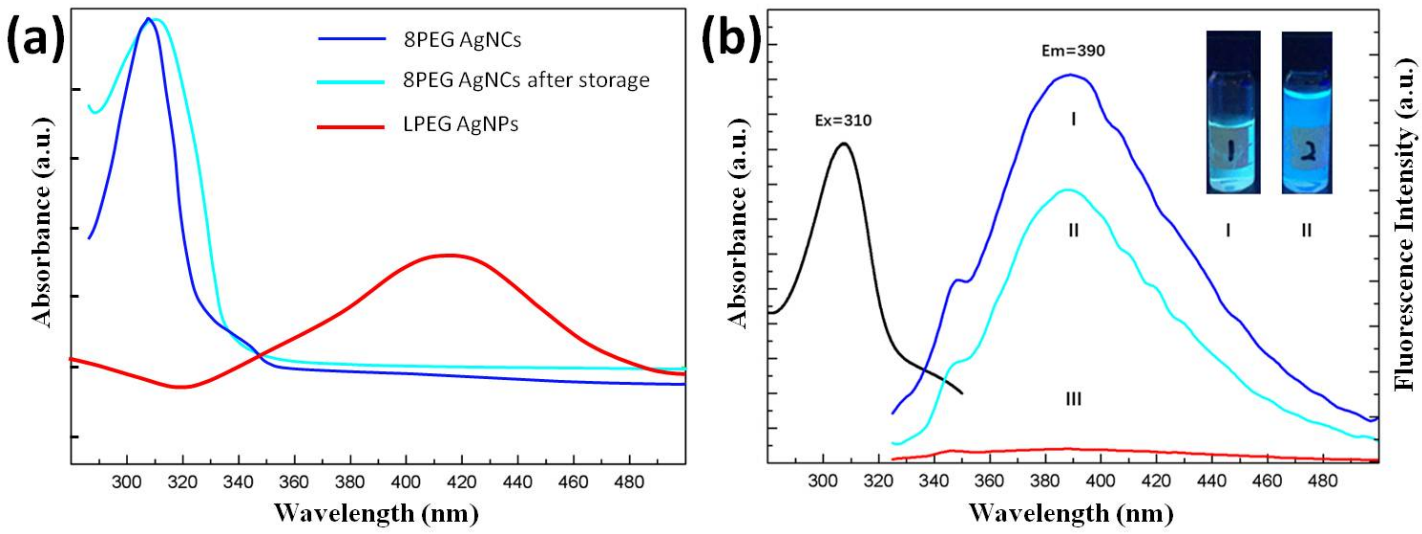

Figure 7. (a) UV/vis absorption spectra and (b) fluorescence spectra of fresh (I), reserved 8PEG-AgNCs solution (II) and linear PEG-AgNCs solution (III). Inset: photographs of fresh (I) and reserved 8PEG-AgNCs solution (II) under and UV light excitation.

After determining the UV absorption peak of the AgNCs, the maximum absorption peak of the fluorescence emission spectrum of the aqueous solution of the AgNCs which passes through the fluorescence spectroscopic characterization can also be determined. Figure $7 \mathrm{~b}$ shows the spectral characterization of the fluorescence of aqueous solutions of AgNCs synthesized by the PEGOA template method, and the fluorescence of the AgNC solutions. The peak position of the emission spectrum is taken as the maximum fluorescence intensity at this wavelength, which corresponds to its UV absorption spectrum, both at $310 \mathrm{~nm}$.

When excited by UV radiation at $310 \mathrm{~nm}$, both AgNCs solutions present a wide fluorescence emission peak at $393 \mathrm{~nm}$ (Figure 7b); for comparison, barely no emission peaks have been found in linear PEG solution, indicating that the nanocages in the gel matrix are essential for the synthesis of the fluorescent AgNCs. The fluorescence quantum yield of 8PEG-AgNCs at $\lambda_{\mathrm{ex}}=310 \mathrm{~nm}$ was measured to be $7.6 \%$ via using quinine sulfate as the reference. In the inset of Figure $7 \mathrm{~b}$, the photographs of fresh and reserved 8PEG-AgNCs in aqueous solution, which emits intense blue fluorescence under a UV lamp, are shown. Moreover, the fluorescence intensity of 8PEG-AgNCs after one year storage only shows 30\% attenuation (Figure $7 \mathrm{~b}$ ), suggesting that the AgNCs are well protected by surrounding PEG chains and exhibit high stability.

The fluorescence stability improved from up to three months to more than one year compared to AgNCs. This shows that the degraded 8PEG molecular chains are fully protected against the AgNCs. AgNCs synthesized using 8PEG as a template did not exhibit significant fluorescence emission at any excitation wavelength under the same conditions. This further suggests that the AgNCs synthesized by 8 PEG are large nanoparticles. However, the greater cross-linking density leads to smaller gel pores, allowing the synthesis of nanoparticles with fluorescent properties. Moreover, the Stokes shift of the AgNCs was calculated to be $83 \mathrm{~nm}$. Compared to the usual Stokes shifts of hundreds, this value is considerably lower. The fluorescence excitation peak is $310 \mathrm{~nm}$, indicating that this AgNCs has an unusual fluorescence resonance energy transfer, which may have potential applications in fluorescence detection.

\subsection{Fluorescent Sensor for Detection of $\mathrm{Cu}^{2+}$ Ions}

Considering the health issue, in drinking water the safe limit of $\mathrm{Cu}^{2+}$ ions has been set at $1.3 \mathrm{ppm}$ (ca. $20 \mu \mathrm{M}$ ) [49]. A low-cost, facile and rapid tracking of $\mathrm{Cu}^{2+}$ ions can be achieved via a fluorescent sensor through fluorescence quenching when $\mathrm{Cu}^{2+}$ ions contact with 8PEG-AgNCs. The selectivity of the 8PEG-AgNCs $(1 \mathrm{mg} / \mathrm{L})$ probe toward $\mathrm{Cu}^{2+}$ ions $(100 \mu \mathrm{M})$, relative to other metal ions $(100 \mu \mathrm{M})$ has 
been tested. When adding $\mathrm{Cu}^{2+}$ ions into the 8PEG-AgNCs solution, fluorescent intensity decreases by $50 \%$, in contrary to no tremendous fluorescence quenching observed in the presence of other metal ions. Figure 8 a reveals that our probes responded toward $\mathrm{Cu}^{2+}$ ions at least 20 -fold more than a variety of competing metal ions, indicating excellent selectivity of $\mathrm{Cu}^{2+}$ detection.
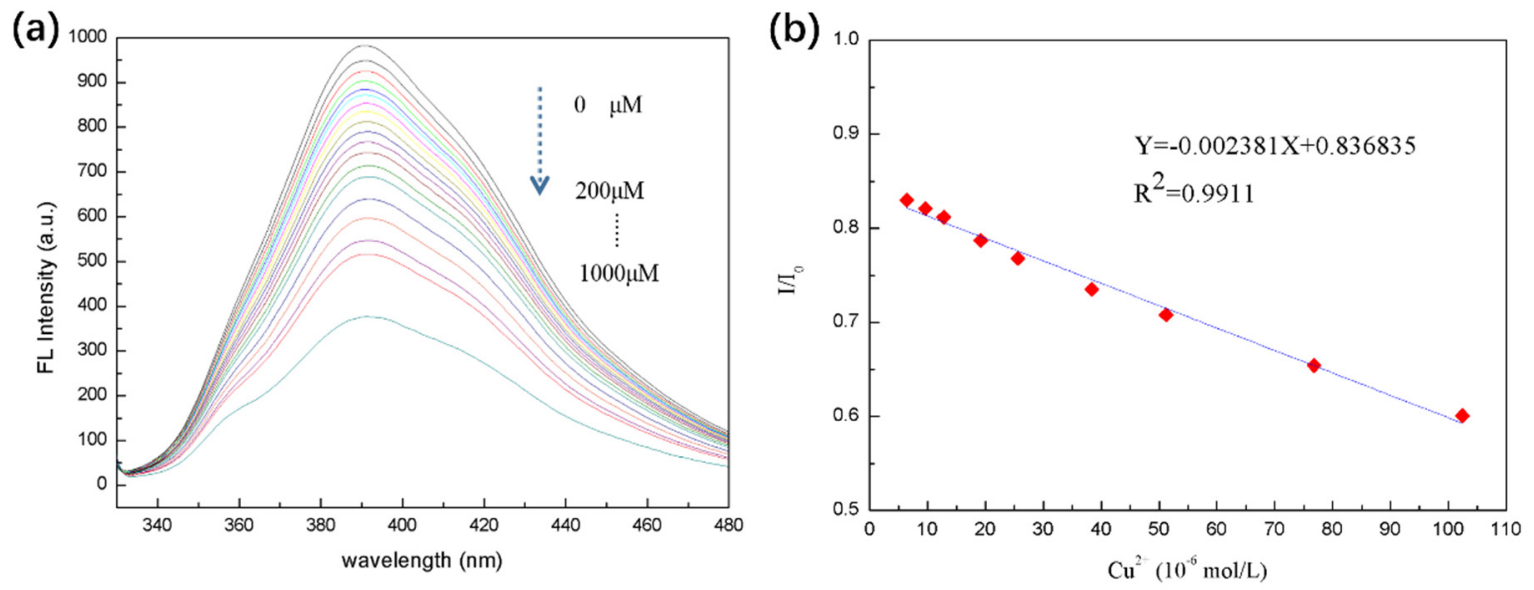

Figure 8. (a) Fluorescent response of 8PEG-AgNCs in the presence of various metal ions $\left(\lambda_{\mathrm{ex}}=310 \mathrm{~nm}\right.$, $\lambda_{\mathrm{em}}=393 \mathrm{~nm}, \mathrm{C}_{\text {metal }}=100 \mu \mathrm{M}, \mathrm{C}_{\mathrm{Cu}}{ }^{2+}=100 \mu \mathrm{M}$ ). (b) Fluorescence emission spectra of 8PEG-AgNCs upon addition of various quantities of $\mathrm{Cu}^{2+}(0-1000 \mu \mathrm{M})$.

It can be demonstrated experimentally that the limit of detection of $\mathrm{Cu}^{2+}$ ions by the 8PEG-AgNCs prepared by this template method is $50 \mathrm{nM}$. This is a value of three standard deviations of the burst fluorescence intensity greater than the instrumental detection after the addition of a certain amount. The 8PEG-AgNCs amount was relatively low, indicating that the 8PEG-AgNCs were sensitive to the presence of $\mathrm{Cu}^{2+}$. The AgNCs prepared by this template method still had strong fluorescence production at $\mathrm{Cu}^{2+}$ ion concentrations higher than $1000 \mu \mathrm{M}$. It also sidelines the stability of the prepared 8PEG-AgNCs, with PEG molecular chains wrapped around the surface of the AgNCs to maintain their certain fluorescence properties.

The fluorescence emission spectra of 8PEG-AgNCs nanohybrids in the presence of $\mathrm{Cu}^{2+}$ with varying concentrations are presented in Figure $8 \mathrm{~b}$. It was found that the fluorescence intensity decreased gradually, when increasing the concentration of $\mathrm{Cu}^{2+}$. Compared with other previous works on $\mathrm{Cu}^{2+}$ detection [50], the dense PEG chain protection not only brings about the unusual stability of AgNCs in aqueous solution, but also prevents AgNCs from complete fluorescence quenching; even the concentrations of $\mathrm{Cu}^{2+}$ ions reach up to $1000 \mu \mathrm{M}$.

The relative fluorescence intensity $\mathrm{I} / \mathrm{I}_{0}$ versus the $\mathrm{Cu}^{2+}$ concentration up to $100 \mu \mathrm{M}$ is plotted in Figure $8 \mathrm{~b}$, where $\mathrm{I}_{0}$ and $\mathrm{I}$ are the fluorescence intensities at $393 \mathrm{~nm}$ in the absence and presence of $\mathrm{Cu}^{2+}$ ions. In the linear range, $\mathrm{AgNC}$ can be used as a fluorescence detection method for $\mathrm{Cu}^{2+}$ ions in the range of $5-100 \mu \mathrm{M}$, relatively. It is a significant improvement over the conventional $\mathrm{Cu}^{2+}$ detection range and is more suitable for practical applications. The detection concentration requirement for $\mathrm{Cu}^{2+}$ detection in drinking water is $20 \mu \mathrm{M}$. The mechanism of fluorescence bursting of AgNCs for the detection of $\mathrm{Cu}^{2+}$ can be based on the following Lineweaver-Burk equation.

$$
\frac{F_{0}}{F}=1+K_{S V} C_{q}
$$

where $F_{0}$ and $F$ are the fluorescence intensities of the AgNCs in the presence and absence of $\mathrm{Cu}^{2+}$, respectively, $K_{s v}$ is the dynamic bursts constant, and $C_{q}$ is the concentration of the bursting agent. From the formula, $F_{0} / F$, if proportional to the concentration of the bursting agent, means that the mechanism of fluorescence bursting is dynamic bursting. Therefore, in this work, the fluorescence burst of 
the AgNCs may be due to a dynamic burst produced by collisions with $\mathrm{Cu}^{2+}$ that transfer energy to the $\mathrm{Cu}^{2+}$.

Linear correlation coefficient $\mathrm{R}^{2}=0.99$ exists between the value of $\mathrm{I} / \mathrm{I}_{0}$ and the concentration of $\mathrm{Cu}^{2+}$ ions over the range $5-100 \mu \mathrm{M}$ as presented in Figure $7 \mathrm{~b}$, satisfying the sensitivity requirement of $\mathrm{Cu}^{2+}$ detection for drinking water $(20 \mu \mathrm{mol} / \mathrm{L})$. The limit of detectable response is $50 \mathrm{nM}(10 \mathrm{ppb})$, based on a signal-to-noise ratio of three. The standard copper detection limit in drinking water is $1.3 \mathrm{ppm}$ in US and $2 \mathrm{ppm}$ in Europe and according to the WHO [51]. The limit of detection by 8PEG-AgNCs is much lower than the existing standard $\mathrm{Cu}^{2+}$ ion detection limit. These results indicate that the as-prepared 8PEG-AgNCs nanohybrids display excellent selectivity and sensitivity toward $\mathrm{Cu}^{2+}$ ions.

In addition to the detection limit and detection range of fluorescence detection, the selectivity of fluorescence detection is also very important. By dropping the same concentrations of different kinds of metal ions commonly found in water into a solution of AgNCs, it was found that AgNCs were only effective in copper (Figure 9). The fluorescence intensity decreases by more than $50 \%$ in the presence of ions, while the addition of other metal ions shows a stronger burst of fluorescence. Only the iron ions showed a small of fluorescence bursting effect, which can be neglected in the actual detection. The $\mathrm{Ca}^{2+}$ ions, which were normally not influenced by the fluorescent sensors [47,52], were neglected in this selectivity test. This showed that the AgNCs prepared by the template method have a very high specificity selection for $\mathrm{Cu}^{2+}$ ions in the fluorescence detection, and in the real water.

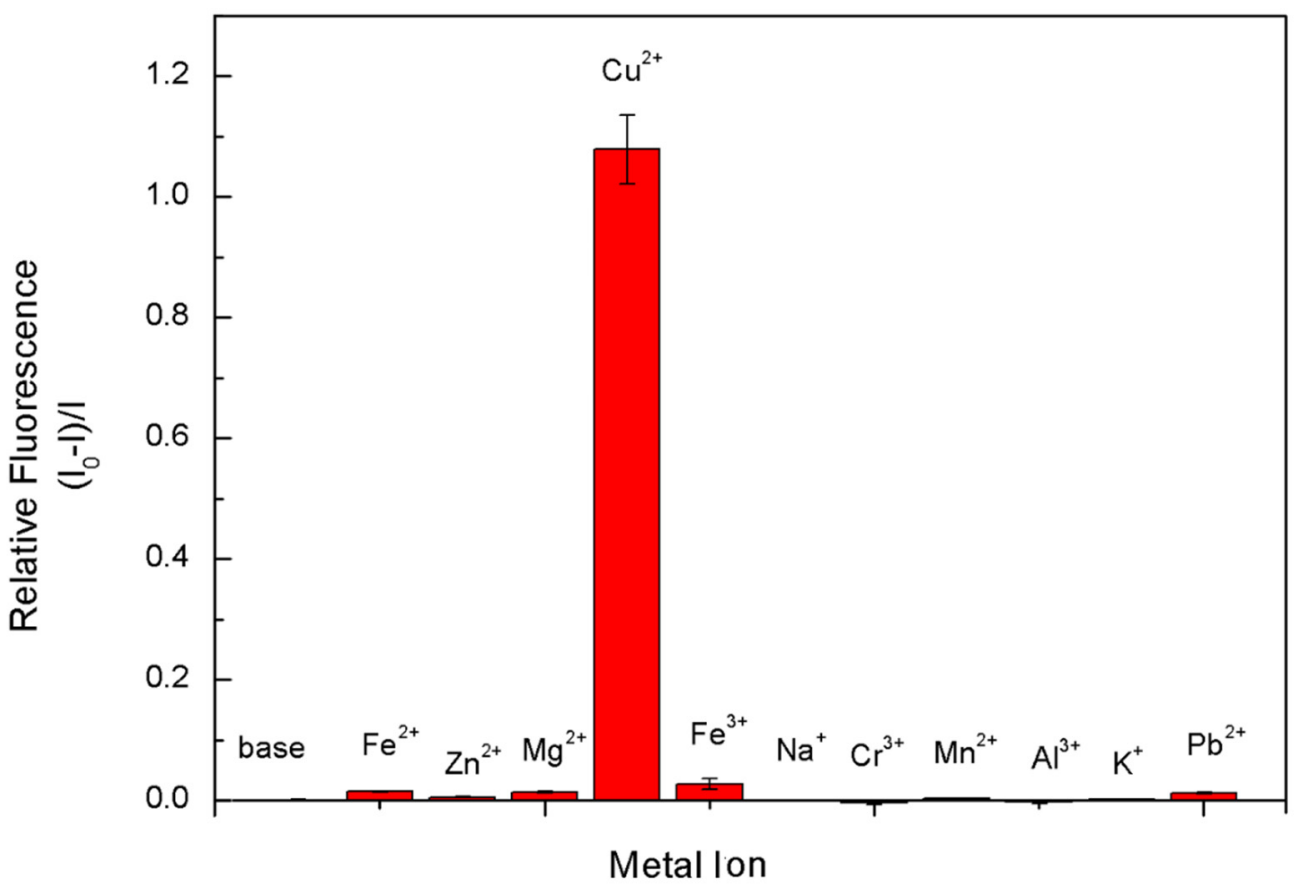

Figure 9. The linear plot of the relative fluorescence intensity $\left(\mathrm{I} / \mathrm{I}_{0}\right)$ of 8 PEG-AgNCs record at $393 \mathrm{~nm}$ versus the concentration of $\mathrm{Cu}^{2+}$.

Comparing with other systems for $\mathrm{Cu}^{2+}$ ion selectivity, the 8PEG-AgNCs system in our work still has superior features. Kaewnok et al. fabricated a fluorescent sensor based on helicene dye bearing hydrazine. The sensor selectively detected $\mathrm{Cu}^{2+}$ ions. The detection limit was $2.6 \mathrm{ppb}$ [53]. Udhayakumari et al. found that 2,3-diaminophenazine, 1,2-diamino-anthraquinone, and 2,4-dinitrophenylhydrazine could work as fluorescent probes for $\mathrm{Cu}^{2+}$ ion selective detection. The phenomena were due to the paramagnetic effect and inhibition of photoinduced electron transfer [54]. In another work, Jung et al. developed a coumarin-based fluorogenic probe as a fluorescent chemosensor. This material exhibited high selectivity for $\mathrm{Cu}^{2+}$ ions due to the fluorescent quenching 
mechanism [55]. The sensor system developed in this work is biodegradable and echo-friendly. In the work of Lee et al., they developed a colorimetric sensor based on a DNAzyme/AuNP for detecting uranium(VI). When exposed to uranium(VI), the solution color changed from purple to red. This was attributed to the fact that uranium(VI) led to the de-aggregation of the functionalized AuNPs. The detection limit was 12 ppb [56]. The limit of detection in this work is lower than this system. A series of comparison was provided in Table 1.

Table 1. Some examples of sensors for $\mathrm{Cu}^{2+}$ ion selectivity.

\begin{tabular}{|c|c|c|c|c|}
\hline Materials & $\begin{array}{c}\mathrm{Cu}^{2+} \\
\text { Selectivity }\end{array}$ & Detection Limit & Proposed Mechanism & Ref. \\
\hline $\begin{array}{l}\text { Helicene dye bearing } \\
\text { hydrazine }\end{array}$ & good & $2.6 \mathrm{ppb}$ & $\begin{array}{l}\text { photoinduced electron } \\
\text { transfer }\end{array}$ & [53] \\
\hline $\begin{array}{l}\text { 2,3-diaminophenazine, } \\
\text { 1,2-diamino-anthraquinone, } \\
\text { 2,4-dinitrophenylhydrazine }\end{array}$ & good & $0.15 \times 10^{-9} \mathrm{M} / \mathrm{L}$ & paramagnetic effect & [54] \\
\hline $\begin{array}{c}\text { Coumarin-based fluorogenic } \\
\text { probe bearing the 2-picolyl } \\
\text { unit }\end{array}$ & good & $0.5 \mu \mathrm{M}$ & quenching mechanism & [55] \\
\hline $\begin{array}{c}\text { Zinc-doped AgInS2 quantum } \\
\text { dots }\end{array}$ & good & $27.3 \mathrm{nM}$ & electron transfer & [52] \\
\hline $\begin{array}{l}\text { Poly (methacrylic acid) } \\
\text { (PMAA)-templated AgNCs }\end{array}$ & good & $8 \mathrm{nM}$ & quenching mechanism & [47] \\
\hline DNA-AgNCs & l & $1.4 \mathrm{mM}$ & $\begin{array}{l}\text { marvelous fluorescent } \\
\text { enhancement in } \\
\text { the presence of } \\
\text { histidine }\end{array}$ & [57] \\
\hline DNA-Cu/AgNCs & good & $2.7 \mathrm{nM}$ & $\begin{array}{l}\text { static quenching } \\
\text { mechanism }\end{array}$ & [58] \\
\hline 8PEG-AgNCs & good & $50 \mathrm{nM}$ & quenching mechanism & $\begin{array}{l}\text { This } \\
\text { work }\end{array}$ \\
\hline
\end{tabular}

In some of the Ag-based systems for ion detection, the mechanism behind them most of the time lays in color change. Firdaus et al. developed a AgNP-based colorimetric sensor for the detection of mercury(II). By adding mercury(II), the solution color changed from yellow to brown. The detection limit was $0.85 \mu \mathrm{M}$ (170 ppb). This sensor has high selectivity for mercury(II) among interfering ions [59]. Some of the work focused on Raman signal change. Liang et al. found that AgNPs along with antigen Cr-EDTA-bis(trimethylsilyl)acetamide (BSA) in immunoassays could be utilized to detect chromium(III) in water. The Raman signal of chromium(III) was decreased when a mixture of chromium(III) solution and AgNPs was flown through the immunoassay. The detection limit was $0.01 \mathrm{ppt}$ to $0.01 \mathrm{ppb}$ [60].

However, the fluorescent sensor provided a lower detection limit and much higher sensitivity. Liu et al. synthesized hydrophilic zinc-doped AgInS2 (AIZS) quantum dots (QDs) through a mini-emulsion/solvent evaporation technique. The AIZS QDs were successfully applied for the selective detection of $\mathrm{Cu}^{2+}$ ions. The detection range was from 0 to $340 \mu \mathrm{M}$ and the limit of detection (LOD) was $27.3 \mathrm{nM}$ [52]. Shang et al. reported poly(methacrylic acid) (PMAA)-templated AgNCs could be utilized to detect $\mathrm{Cu}^{2+}$ ions. This was due to the quenching effect of functionalized AgNCs and $\mathrm{Cu}^{2+}$ ions. The sensing range was from $1.0 \times 10^{-8} \mathrm{M}$ to $6.0 \times 10^{-6} \mathrm{M}$ and the detection limit was $8 \mathrm{nM}$ [47]. According to the similarity of our AgNCs and those in the literature, we assumed that the mechanism behind was fluorescent quenching.

When the system was complexed with copper atoms, the sensitivity was even better. Su et al. developed a sensor system based on 3-mercaptopropionic acid (MPA) and DNA-Cu/Ag nanoclusters (NCs) for $\mathrm{Cu}^{2+}$ ion detection. This was attributed to the fact that the $\mathrm{Cu}^{2+}$ ions resulted in the oxidation 
of MPA to form a disulfide compound. This compound led to recovery of the fluorescence of the DNA-Cu/AgNCs. The detection range was from 5 to $200 \mathrm{nM}$. The limit of detection was $2.7 \mathrm{nM}$ [58]. This complex combination will be considered in our next working system for enhancing the detection sensitivity.

After the preparation of AgNCs by this facile template method in this work, the relationship between the degree of fluorescence deactivation and the amount of copper ions added was studied. The results illustrated the capability of 8 PEG-AgNCs as fluorescent sensor for $\mathrm{Cu}^{2+}$ ions. By comparison with other literature, the mechanism of the fluorescence burst between the template synthesized $\mathrm{AgNCs}$ and $\mathrm{Cu}^{2+}$ ions is assumed to be a fluorescent quenching mechanism. The fluorescence detection test showed that the synthesized AgNCs are suitable for the online monitoring of $\mathrm{Cu}^{2+}$ ions in real environments.

\section{Conclusions}

In summary, we presented a novel, facile and low-cost method for one-pot, in situ synthesis of highly fluorescent AgNCs via a gel-mediated process. Well-dispersed AgNCs coated with PEG presents extreme long-term stability. It has been proved that nanocages inside the gel matrix play a crucial role in the formation of nanoclusters, due to the volume restriction effect. The synthesis of AgNCs using eight-armed PEG templates has the advantages of a simple method, no need for reducing agents, high stability and good water solubility. In the next stage, the as-synthesized AgNCs utilized for $\mathrm{Cu}^{2+}$ detection reveal excellent selectivity and sensitivity. Study of the relationship between the degree of fluorescence extinction and the amount of $\mathrm{Cu}^{2+}$ ions added indicated the corresponding detection limits, linear range and linear correlation. The linear detection of $\mathrm{Cu}^{2+}$ ions by AgNCs synthesized by this template method ranged from 5-100 $\mu \mathrm{mol} / \mathrm{L}$. This novel gel-mediated strategy displays a unique combination of advantages, namely simple and versatile preparation, long-term stability, controllable nanocluster growth, and the degradability of the template. These advantages will be highly interesting in the nanotechnology field.

Author Contributions: G.Z. and X.Z. designed and performed the experiments, as well as analyzed the data; X.Z. wrote the paper; Z.S. and G.W. proposed this project and supervised the experiments; G.W. conducted final proof reading of the manuscript. All authors have read and agreed to the published version of the manuscript.

Funding: The authors greatly acknowledge the National Natural Science Foundation of China (NSFC, Grant No. 51873016 and 51873225) and the Fundamental Research Funds for the Central Universities (JD2014) for financial support.

Acknowledgments: The authors greatly acknowledge the National Natural Science Foundation of China (NSFC, Grant No. 51873016 and 51873225) and the Fundamental Research Funds for the Central Universities (JD2014) for financial support.

Conflicts of Interest: The authors declare no conflict of interest.

\section{References}

1. Chakraborty, I.; Pradeep, T. Atomically precise clusters of noble metals: Emerging link between atoms and nanoparticles. Chem. Rev. 2017, 117, 8208-8271. [CrossRef] [PubMed]

2. Baral, A.; Basu, K.; Ghosh, S.; Bhattacharyya, K.; Roy, S.; Datta, A.; Banerjee, A. Size specific emission in peptide capped gold quantum clusters with tunable photoswitching behavior. Nanoscale 2017, 9, 4419-4429. [CrossRef] [PubMed]

3. Shang, L.; Dong, S.; Nienhaus, G.U. Ultra-small fluorescent metal nanoclusters: Synthesis and biological applications. Nano Today 2011, 6, 401-418. [CrossRef]

4. Yu, X.; Liu, W.; Deng, X.; Yan, S.; Su, Z. Gold nanocluster embedded bovine serum albumin nanofibers-graphene hybrid membranes for the efficient detection and separation of mercury ion. Chem. Eng. J. 2018, 335, 176-184. [CrossRef]

5. Yu, X.; Wang, Z.; Su, Z.; Wei, G. Design, fabrication, and biomedical applications of bioinspired peptide-inorganic nanomaterial hybrids. J. Mater. Chem. B 2017, 5, 1130-1142. [CrossRef] 
6. Zhang, W.; Lin, D.; Wang, H.; Li, J.; Nienhaus, G.U.; Su, Z.; Wei, G.; Shang, L. Supramolecular self-assembly bioinspired synthesis of luminescent gold nanocluster-embedded peptide nanofibers for temperature sensing and cellular imaging. Bioconjugate Chem. 2017, 28, 2224-2229. [CrossRef]

7. Ritchie, C.M.; Johnsen, K.R.; Kiser, J.R.; Antoku, Y.; Dickson, R.M.; Petty, J.T. Ag nanocluster formation using a cytosine oligonucleotide template. J. Phys. Chem. C 2007, 111, 175-181. [CrossRef]

8. New, S.; Lee, S.; Su, X. DNA-templated silver nanoclusters: Structural correlation and fluorescence modulation. Nanoscale 2016, 8, 17729-17746. [CrossRef]

9. Sharma, J.; Yeh, H.-C.; Yoo, H.; Werner, J.H.; Martinez, J.S. A complementary palette of fluorescent silver nanoclusters. Chem. Commun. 2010, 46, 3280-3282. [CrossRef]

10. Mei, L.; Teng, Z.; Zhu, G.; Liu, Y.; Zhang, F.; Zhang, J.; Li, Y.; Guan, Y.; Luo, Y.; Chen, X. Silver nanocluster-embedded zein films as antimicrobial coating materials for food packaging. ACS Appl. Mater. Interfaces 2017, 9, 35297-35304. [CrossRef]

11. Ma, Y.; Shen, X.-F.; Liu, F.; Pang, Y.-H. Colorimetric detection toward halide ions by a silver nanocluster hydrogel. Talanta 2020, 211, 120717. [PubMed]

12. Ershov, B.; Janata, E.; Henglein, A.; Fojtik, A. Silver atoms and clusters in aqueous solution: Absorption spectra and the particle growth in the absence of stabilizing $\mathrm{Ag}^{+}$ions. J. Phys. Chem. 1993, 97, 4589-4594.

13. Henglein, A. Small-particle research: Physicochemical properties of extremely small colloidal metal and semiconductor particles. Chem. Rev. 1989, 89, 1861-1873.

14. Udayabhaskararao, T.; Pradeep, T. New protocols for the synthesis of stable Ag and Au nanocluster molecules. J. Phys. Chem. Lett. 2013, 4, 1553-1564. [PubMed]

15. Kumar, S.; Bolan, M.D.; Bigioni, T.P. Glutathione-stabilized magic-number silver cluster compounds. J. Am. Chem. Soc. 2010, 132, 13141-13143.

16. Kitazawa, H.; Albrecht, K.; Yamamoto, K. Synthesis of a dendrimer reactor for clusters with a magic number. Chem. Lett. 2012, 41, 828-830.

17. Xu, H.; Suslick, K.S. Sonochemical synthesis of highly fluorescent Ag nanoclusters. ACS Nano 2010, 4, 3209-3214. [PubMed]

18. Adhikari, B.; Banerjee, A. Short-peptide-based hydrogel: A template for the in situ synthesis of fluorescent silver nanoclusters by using sunlight. Chem. A Eur. J. 2010, 16, 13698-13705.

19. Yu, J.; Patel, S.A.; Dickson, R.M. In vitro and intracellular production of peptide-encapsulated fluorescent silver nanoclusters. Angew. Chem. Int. Ed. 2007, 46, 2028-2030.

20. Copp, S.M.; Bogdanov, P.; Debord, M.; Singh, A.; Gwinn, E. Base motif recognition and design of DNA templates for fluorescent silver clusters by machine learning. Adv. Mater. 2014, 26, 5839-5845.

21. Tan, R.; He, Y.; Zhu, Y.; Xu, B.; Cao, L. Hydrothermal preparation of mesoporous $\mathrm{TiO}_{2}$ powder from $\mathrm{Ti}\left(\mathrm{SO}_{4}\right)_{2}$ with poly (ethylene glycol) as template. J. Mater. Sci. 2003, 38, 3973-3978. [CrossRef]

22. Shen, Z.; Duan, H.; Frey, H. Water-soluble fluorescent Ag nanoclusters obtained from multiarm star poly (acrylic acid) as "molecular hydrogel" templates. Adv. Mater. 2007, 19, 349-352. [CrossRef]

23. Dai, Y.; Hu, X.; Wang, C.; Chen, D.; Jiang, X.; Zhu, C.; Yu, B.; Qiu, J. Fluorescent Ag nanoclusters in glass induced by an infrared femtosecond laser. Chem. Phys. Lett. 2007, 439, 81-84. [CrossRef]

24. Huang, Z.; Pu, F.; Lin, Y.; Ren, J.; Qu, X. Modulating DNA-templated silver nanoclusters for fluorescence turn-on detection of thiol compounds. Chem. Commun. 2011, 47, 3487-3489.

25. Sharma, J.; Rocha, R.C.; Phipps, M.L.; Yeh, H.-C.; Balatsky, K.A.; Vu, D.M.; Shreve, A.P.; Werner, J.H.; Martinez, J.S. A DNA-templated fluorescent silver nanocluster with enhanced stability. Nanoscale 2012, 4, 4107-4110. [CrossRef]

26. Shang, L.; Dong, S. Facile preparation of water-soluble fluorescent silver nanoclusters using a polyelectrolyte template. Chem. Commun. 2008, 1088-1090. [CrossRef]

27. Barthel, M.J.; Angeloni, I.; Petrelli, A.; Avellini, T.; Scarpellini, A.; Bertoni, G.; Armirotti, A.; Moreels, I.; Pellegrino, T. Synthesis of highly fluorescent copper clusters using living polymer chains as combined reducing agents and ligands. ACS Nano 2015, 9, 11886-11897. [CrossRef]

28. Shang, G.; Li, C.; Wen, G.; Zhang, X.; Liang, A.; Jiang, Z. A new silver nanochain SERS analytical platform to detect trace hexametaphosphate with a rhodamine S molecular probe. Luminescence 2016, 31, 640-648.

29. Schmidt, E.W. Hydrazine and Its Derivatives: Preparation, Properties, Applications, 2 Volume Set; John Wiley \& Sons: Hoboken, NJ, USA, 2001. 
30. Choi, S.; Dickson, R.M.; Yu, J. Developing luminescent silver nanodots for biological applications. Chem. Soc. Rev. 2012, 41, 1867-1891.

31. Wang, S.; Meng, X.; Das, A.; Li, T.; Song, Y.; Cao, T.; Zhu, X.; Zhu, M.; Jin, R. A 200-fold quantum yield boost in the photoluminescence of silver-doped $\mathrm{AgxAu}_{25}-\mathrm{x}$ nanoclusters: The 13th silver atom matters. Angew. Chem. 2014, 126, 2408-2412.

32. Zinchenko, A.; Miwa, Y.; Lopatina, L.I.; Sergeyev, V.G.; Murata, S. DNA hydrogel as a template for synthesis of ultrasmall gold nanoparticles for catalytic applications. ACS Appl. Mater. Interfaces 2014, 6, 3226-3232. [CrossRef]

33. Liu, W.; Zhang, X.; Wei, G.; Su, Z. Reduced graphene oxide-based double network polymeric hydrogels for pressure and temperature sensing. Sensors 2018, 18, 3162. [CrossRef] [PubMed]

34. Liu, W.; Zhang, W.; Yu, X.; Zhang, G.; Su, Z. Synthesis and biomedical applications of fluorescent nanogels. Polym. Chem. 2016, 7, 5749-5762. [CrossRef]

35. Zhang, J.; Xu, S.; Kumacheva, E. Photogeneration of fluorescent silver nanoclusters in polymer microgels. Adv. Mater. 2005, 17, 2336-2340. [CrossRef]

36. Chakraborty, I.; Udayabhaskararao, T.; Pradeep, T. Luminescent sub-nanometer clusters for metal ion sensing: A new direction in nanosensors. J. Hazard. Mater. 2012, 211, 396-403. [CrossRef] [PubMed]

37. Ma, B.; Dang, W.; Yang, Z.; Chang, J.; Wu, C. MoS2 Nanoclusters-based biomaterials for disease-impaired wound therapy. Appl. Mater. Today 2020, 20, 100735. [CrossRef]

38. Roy, S.; Banerjee, A. Amino acid based smart hydrogel: Formation, characterization and fluorescence properties of silver nanoclusters within the hydrogel matrix. Soft Matter 2011, 7, 5300-5308. [CrossRef]

39. Guo, S.R.; Gong, J.Y.; Jiang, P.; Wu, M.; Lu, Y.; Yu, S.H. Biocompatible, luminescent silver@ phenol formaldehyde resin core/shell nanospheres: Large-scale synthesis and application for in vivo bioimaging. Adv. Funct. Mater. 2008, 18, 872-879. [CrossRef]

40. Zhang, Z.; Li, Q.; Yesildag, C.; Bartsch, C.; Zhang, X.; Liu, W.; Loebus, A.; Su, Z.; Lensen, M.C. Influence of network structure on the crystallization behavior in chemically crosslinked hydrogels. Polymers 2018, 10, 970. [CrossRef]

41. Zhang, Z.; Loebus, A.; de Vicente, G.; Ren, F.; Arafeh, M.; Ouyang, Z.; Lensen, M.C. Synthesis of poly (ethylene glycol)-based hydrogels via amine-michael type addition with tunable stiffness and postgelation chemical functionality. Chem. Mater. 2014, 26, 3624-3630. [CrossRef]

42. Ren, F.; Yesildag, C.; Zhang, Z.; Lensen, M.C. Functional PEG-hydrogels convey gold nanoparticles from silicon and aid cell adhesion onto the nanocomposites. Chem. Mater. 2017, 29, 2008-2015.

43. Liz-Marzán, L.M.; Lado-Touriño, I. Reduction and stabilization of silver nanoparticles in ethanol by nonionic surfactants. Langmuir 1996, 12, 3585-3589.

44. Luo, C.; Zhang, Y.; Zeng, X.; Zeng, Y.; Wang, Y. The role of poly (ethylene glycol) in the formation of silver nanoparticles. J. Colloid Interface Sci. 2005, 288, 444-448.

45. Kumar, R.; Chaudhary, P.; Nimesh, S.; Chandra, R. Polyethylene glycol as a non-ionic liquid solvent for Michael addition reaction of amines to conjugated alkenes. Green Chem. 2006, 8, 356-358.

46. Zheng, J.; Dickson, R.M. Individual water-soluble dendrimer-encapsulated silver nanodot fluorescence. J. Am. Chem. Soc. 2002, 124, 13982-13983.

47. Shang, L.; Dong, S. Silver nanocluster-based fluorescent sensors for sensitive detection of Cu(II). J. Mater. Chem. 2008, 18, 4636-4640.

48. Wang, C.; Huang, Y. Facile preparation of fluorescent Ag-clusters-chitosan-hybrid nanocomposites for bio-applications. New J. Chem. 2014, 38, 657-662.

49. Liu, S.; Tian, J.; Wang, L.; Zhang, Y.; Qin, X.; Luo, Y.; Asiri, A.M.; Al-Youbi, A.O.; Sun, X. Hydrothermal treatment of grass: A low-cost, green route to nitrogen-doped, carbon-rich, photoluminescent polymer nanodots as an effective fluorescent sensing platform for label-free detection of $\mathrm{Cu}(\mathrm{II})$ ions. Adv. Mater. 2012, 24, 2037-2041.

50. Karaoglu, K.; Yilmaz, F.; Menteşe, E. A new fluorescent "turn-off" coumarin-based chemosensor: Synthesis, structure and Cu-selective Fluorescent sensing in water samples. J. Fluoresc. 2017, 27, 1293-1298.

51. Dalmieda, J.; Kruse, P. Metal cation detection in drinking water. Sensors 2019, 19, 5134.

52. Liu, Y.; Zhu, T.; Deng, M.; Tang, X.; Han, S.; Liu, A.; Bai, Y.; Qu, D.; Huang, X.; Qiu, F. Selective and sensitive detection of copper (II) based on fluorescent zinc-doped AgInS2 quantum dots. J. Lumin. 2018, 201, 182-188. [CrossRef] 
53. Kaewnok, N.; Petdum, A.; Sirirak, J.; Charoenpanich, A.; Panchan, W.; Sahasithiwat, S.; Sooksimuang, T.; Wanichacheva, N. Novel $\mathrm{Cu}^{2+}$-specific "Turn-ON" fluorescent probe based on [5] helicene with very large Stokes shift and its potential application in living cells. New J. Chem. 2018, 42, 5540-5547. [CrossRef]

54. Udhayakumari, D.; Velmathi, S.; Sung, Y.-M.; Wu, S.-P. Highly fluorescent probe for copper (II) ion based on commercially available compounds and live cell imaging. Sens. Actuators B Chem. 2014, 198, 285-293. [CrossRef]

55. Jung, H.S.; Kwon, P.S.; Lee, J.W.; Kim, J.I.; Hong, C.S.; Kim, J.W.; Yan, S.; Lee, J.Y.; Lee, J.H.; Joo, T. Coumarin-derived $\mathrm{Cu}^{2+}$-selective fluorescence sensor: Synthesis, mechanisms, and applications in living cells. J. Am. Chem. Soc. 2009, 131, 2008-2012. [CrossRef] [PubMed]

56. Lee, J.H.; Wang, Z.; Liu, J.; Lu, Y. Highly sensitive and selective colorimetric sensors for uranyl $\left(\mathrm{UO}_{2}{ }^{2+}\right)$ : Development and comparison of labeled and label-free DNAzyme-gold nanoparticle systems. J. Am. Chem. Soc. 2008, 130, 14217-14226. [CrossRef]

57. Zhou, Y.; Zhou, T.; Zhang, M.; Shi, G. A DNA-scaffolded silver nanocluster/Cu $\mathrm{Cu}_{2}+$ ensemble as a turn-on fluorescent probe for histidine. Analyst 2014, 139, 3122-3126. [CrossRef]

58. Su, Y.-T.; Lan, G.-Y.; Chen, W.-Y.; Chang, H.-T. Detection of copper ions through recovery of the fluorescence of DNA-templated copper/silver nanoclusters in the presence of mercaptopropionic acid. Anal. Chem. 2010, 82, 8566-8572. [CrossRef]

59. Firdaus, M.L.; Fitriani, I.; Wyantuti, S.; Hartati, Y.W.; Khaydarov, R.; McAlister, J.A.; Obata, H.; Gamo, T. Colorimetric detection of mercury (II) ion in aqueous solution using silver nanoparticles. Anal. Sci. 2017, 33, 831-837. [CrossRef]

60. Liang, J.; Liu, H.; Lan, C.; Fu, Q.; Huang, C.; Luo, Z.; Jiang, T.; Tang, Y. Silver nanoparticle enhanced Raman scattering-based lateral flow immunoassays for ultra-sensitive detection of the heavy metal chromium. Nanotechnology 2014, 25, 495501. [CrossRef]

(C) 2020 by the authors. Licensee MDPI, Basel, Switzerland. This article is an open access article distributed under the terms and conditions of the Creative Commons Attribution (CC BY) license (http://creativecommons.org/licenses/by/4.0/). 